University of Washington Tacoma

UW Tacoma Digital Commons

Education Publications

Education

$10-2003$

\title{
Helping Hands? Experts Examine Curricular Alignment at Kentridge High School
}

Samantha E. Ketover

Kentridge High School

Jose Rios

University of Washington - Tacoma Campus, jrios@u.washington.edu

Follow this and additional works at: https://digitalcommons.tacoma.uw.edu/education_pub

Part of the Curriculum and Instruction Commons, and the Science and Mathematics Education Commons

\section{Recommended Citation}

Ketover, Samantha E. and Rios, Jose, "Helping Hands? Experts Examine Curricular Alignment at Kentridge High School" (2003).

Education Publications. 2.

https://digitalcommons.tacoma.uw.edu/education_pub/2

This Article is brought to you for free and open access by the Education at UW Tacoma Digital Commons. It has been accepted for inclusion in Education Publications by an authorized administrator of UW Tacoma Digital Commons. 


\title{
Helping Hands? \\ Experts Examine Curricular Alignment at Kentridge High School
}

\author{
Samantha E. Ketover José M. Rios
}

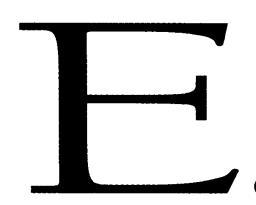

ducation reform is nothing new; however, from our point of view, the tension between assessment and accountability is at an all-time high. Currently, 48 states administer state-mandated tests and 36 states publish annual report cards on school performance (Olson, 1999). Kentucky, for example, links student achievement on standardized assessments to teacher pay (Din, 1996). This link has contributed to an increasingly volatile situation, where some teachers refuse to administer high-stakes tests. They end up serving lengthy suspensions and battling administrators over the validity of such tests (http://www.pdkintl.org/ kappan/koha0101.htm). As a nation, we are faced with a political and educational situation in which assessment and accountability are colliding. Accountability is a key word in all educational circles and permeates educational debates from the national level down to the individual classroom level.

SAMANTHA E. KetOVER, M.Ed., is a science teacher at Kentridge High School, Kent, WA 98031. JosÉ M. RIOS, Ph.D., is Assistant Professor at University of Washington, Tacoma, WA 98402.
In February 1990, several national educational goals were adopted after a landmark educational summit in late 1989. Chief among them was the goal that by the year 2000, students from the United States would be ranked first in the world in math and science (Doran et al., 1994). After the adoption of this goal, national and state standards were developed, including the National Science Education Standards (NRC, 1996). The wave of educational reform continues to the present day, even though practitioners and researchers warn of the "perils associated with rigid standards that stress testing and teacher accountability" (Biddle, 1998, p. 165). Two current examples of this national-to-local trickle down effect include the Washington State Essential Academic Learning Requirements (EALRs: Washington Commission on Student Learning, 1998) and the Oregon State Standards (Conly \& Goldman, 1998).

As accountability in education trickled down from the national to the state level, so has the accompanying

continued on page 574 


\section{Helping Hands}

continuation from page 572

tension. Researchers have compared states using standards, educational indicators, and accountability systems (Blank, 1990; Olson, 1999). For example, Olson found that 48 states administer state-wide standardized tests, 36 states issue school report cards, 19 states issue school ratings, 19 states provide assistance for lower performing schools, 16 states administer sanctions for chronically failing schools, and 14 states provide monetary rewards for well performing schools. These data have been compiled into reports, such as the National Assessment of Educational Progress 1996 Science Report Card for the Nation and the States, which includes performance data comparing one state to another. Many states, including Washington, have used these reports to push for the adoption of clearer standards and assessments tools.

Washington eighth graders, for example, performed at or around the national average in the 1996 NAEP science data. States have developed their own tests to assess student learning toward state standards. Washington, for example, developed the Washington State Essential Academic Learning Requirements and the Washington Assessment of Student Learning (WASL) to assess students and hold parties (i.e., teachers and principals) accountable. Washington state also established the Academic Achievement and Accountability Commission, dubbed the "A+ Commission," to "provide oversight of a K-12 education accountability system and to make recommendations to the Legislature regarding key components of this system." (http://www.k12.wa.us/accountability/). As assessment and accountability trickles down to the state level, research that examines this phenomenon continues to grow.

Studies of Oregon, Kentucky, Texas, and Washington teachers underscore the effects of this issue (Conly, 1998; Corbett, 1995; Din, 1996; Lutz, 1990; Laguardia, 1999). In the Corbett study, teachers cited several impacts of state assessments including:

\section{1. disruption of their work lives}

2. a decreased reliance on teachers' professional judgment

3. concerns over liability

4. increased time demands

5. resignations over pressure to meet accountability expectations.

Closer to home, teachers in Washington view accountability and assessment as a most worrisome issue (Laguardia, 1999; Rios, 2002). Balancing the voices of concern over accountability and assessment on the state level are voices reminding people that the test scores do not represent the whole issue.

One powerful voice, the Connecticut State Board of Education, reminds us that there is more to assessment than just standardized tests. Released in 2000, "Measuring Success" reminds people of the "... danger of overemphasizing state test scores to evaluate a student's, a school's, or a district's performance that can result in an inappropriate narrowing of the curriculum and inappropriate classroom instructional strategies." The State Commissioner of Education, Theodore Sergi, called for balance in student assessment. He stated, "The more you start to use the tests for lists of schools, and for rankings of schools, and to identify students for graduation, you start to stray away from the purpose of the program. We believe we can have strong accountability and a focus on achievement, without the nastiness and the harm." (http://www.edweek.org/ew/ew printstory.cfm?slug=05conn.h20.)

As one looks at the current trends in Washington, where do we stand? In Washington, the WASL and the standards movement provide the public and professionals with numbers and data, but are they the only data? Clearly WASL scores are not the only data available, nor should they be (Shannon, 2000). One particular high school, Kentridge, experimented with examining assessment and accountability in a different way.

\section{Assessment at Kentridge High School}

Kentridge High School is located within the Kent School District (KSD). In response to current national trends, the KSD has developed its own Student Learning Objectives (SLOs) to further teacher and student pursuit of accountability. Teachers not only grade students academically, but also use an Employability and Life Skills Assessment, which evaluates students in four areas:

1. commitment to quality

2. work habits

3. attitude

4. quantity of work.

Yet with this proactive stance toward accountability, the KSD still struggles with a basic question: "How well does our science curriculum align with existing standards?"

In 1998, Kentridge's teachers were charged with creating a common syllabus for all biology courses, leading to the creation (and subsequent refinement) of a Student Achievement Action Plan (SAAP). As staff 
developed common syllabi, they discussed how to ensure that students learned the same material from different teachers. An important part of the process was to identify course outcomes. These course outcomes reflected what staff identified as essential content knowledge and process skills for all students completing these courses. After developing course outcomes, the staff created benchmarks for student achievement at three levels: basic, proficient, and mastery. Finally, the staff developed assessments, pre- and post-tests, which would accurately identify a student's performance on an outcome. Rather than rely on test scores alone, teachers at Kentridge decided to enlist the assistance of experts to determine the strength of alignment among standards, outcomes, and assessments.

\section{Purpose of the Study}

The purpose of this study was to examine alignment issues for one biology unit, Classification and Evolution. Specifically, we explored four questions:

- To what extent are the National Standards and the EALRs aligned?

- To what extent are the EALRs aligned with the course outcomes?

- To what extent are the course outcomes aligned with the benchmarks?

- To what extent are the benchmarks aligned with the assessment?

\section{Participants}

Samantha Ketover, a science teacher at Kentridge High School, and José Rios, an assistant professor at a local public university, recruited ten experts for this study. The experts were either faculty members from local universities or science teachers with more than five years of classroom experience. Each expert was sent a packet containing the science EALRs, course outcomes and benchmarks, sample assessments, and a scoring rubric. Their charge was to evaluate the KSD curriculum and assessment tools for alignment.

\section{Evaluation Tools}

The document containing the biology course outcomes specified both the content and performance outcomes for the introductory biology class. The document also contained specific benchmarks for content and performance outcomes. For each outcome, the teachers defined three levels of performance: basic, proficient, and mastery. They also determined what materials would serve as evidence for each level of performance. Each student was assessed for each outcome based on the specific benchmarks. The assessments

Table 1. Categories in the Alignment Assessment Tool
$\begin{aligned} & \text { CATEGORY } \\
& \text { NUMBER }\end{aligned}$
\begin{tabular}{|cl}
\hline 1 & CATEGORY DESCRIPTION \\
\hline 2 & Alignment between EALR and course outcome \\
\hline 3 & Alignment between course outcomes and student achievement benchmark \\
\hline 4 & Do course assessments reflect EALRs? \\
\hline 5 & Do assessments reflect course outcomes? \\
\hline 6 & Do assessments reflect student achievement benchmarks? \\
\hline
\end{tabular}

Table 2. Expert Means and SD Across All Six
Categories on the Alignment Assessment Tool

\begin{tabular}{|ccc|}
$\begin{array}{c}\text { EXPERT } \\
\text { NUMBER }\end{array}$ & $\begin{array}{c}\text { MEAN SCORE ACROSS } \\
\text { ALL SIX CATEGORIES }\end{array}$ & $\begin{array}{c}\text { STANDARD DEVIATION } \\
\text { FOR EXPERT }\end{array}$ \\
\hline 1 & 3.33 & .52 \\
\hline 2 & 3.50 & .55 \\
\hline 3 & 3.67 & .52 \\
\hline 4 & 3.67 & .52 \\
\hline 5 & 3.00 & .63 \\
\hline 6 & 3.67 & .52 \\
\hline 7 & 3.67 & .52 \\
\hline 8 & 3.20 & .45 \\
\hline 9 & 3.17 & .41 \\
\hline 10 & 3.17 & .41 \\
\hline
\end{tabular}

Note: 1-unsatisfactory, 2-emerging, 3-competent, 4-superior; experts $1-5$ are $\mathrm{K}-12$ teachers, $6-10$ are university professors.

included paper and pencil tests and performance tasks.

Alignment between the documents was determined using the criteria and rubrics established by Webb (1997). Webb's original work was designed for use at the district level. In order to use the tool at the classroom level, we modified the language of the criteria and rubrics to match Kentridge's course documents. 


\begin{tabular}{|c|c|}
\hline NAME OF THEMES & DEFINITION \\
\hline $\begin{array}{l}\text { Alignment Gap: } \\
\text { Speciation }\end{array}$ & $\begin{array}{l}\text { Lack of alignment noted by experts between EALR 1.2, EALR 1.1.5 } \\
\text { Benchmark 3, and the EALR concept of speciation and the course } \\
\text { documents (see Appendix A). }\end{array}$ \\
\hline $\begin{array}{l}\text { Alignment Gap: } \\
\text { Classification }\end{array}$ & $\begin{array}{l}\text { Experts comment on lack of alignment between classification } \\
\text { content outcome and the course assessments. }\end{array}$ \\
\hline The Experts Divided & $\begin{array}{l}\text { The experts divide evenly in their perception of the adequacy of } \\
\text { the alignment between documents. }\end{array}$ \\
\hline $\begin{array}{l}\text { Lack of Parallel } \\
\text { Construction }\end{array}$ & $\begin{array}{l}\text { The experts comment on the inadequacy of the student } \\
\text { achievement benchmark construction. }\end{array}$ \\
\hline $\begin{array}{l}\text { Instructional Activity } \\
\text { vs. Assessment Activity }\end{array}$ & $\begin{array}{l}\text { Experts perceived several activities that this author } \\
\text { termed to be assessments as instructional activities. }\end{array}$ \\
\hline
\end{tabular}

\section{Results}

\section{Assessment Categories}

Table 1 describes the six categories used by the experts recruited to score the alignment between the outcome, benchmark, and assessment documents.

\section{Quantitative Data}

Table 2 summarizes the means and standards deviations across all six categories on the Alignment Assessment Tool. The overall means was 3.43 and 3.38 for the teacher experts and university professors, respectively. The difference between these means was not statistically significant (alpha $=.05)$.

\section{Qualitative Data}

After reading evaluations from all ten experts, we also found five themes relating to our study questions.

\section{Discussion}

\section{By the Numbers}

Using a four-point scale, all of the experts scored Ms. Ketover and her colleagues as competent in aligning the documents they were asked to create. A score of a four corresponded to superior, three was competent, two was emerging, and a score of one was unsatisfactory. The overall means of the experts ranged from 3.67 to 3.00 , with a small range of standard deviations (i.e., .41 to .63.) Looking at the scores across all of the categories, the scores were once again competent. When considering classification. the means for each category, the overall means ranged from 3.10 to 3.70 , the SD from .32 to .57 .

To us, these findings are reassuring. Having ten experts rate the work under consideration as competent gives us confidence to move forward with further development of the course documents and expert review of those documents. The biology teachers at Kentridge High School are leading the way for other teachers in the South Puget Sound. It is important for them to be successful, so that those who follow have access to a useful model. Examining the qualitative results, we found that their original concerns about alignment were well founded.

\section{EALR Alignment}

Although the ratings were reassuring, we entered the study with concerns about alignment among the course documents. In order to evaluate this issue more closely, we asked the experts to provide comments as they worked through each part of the evaluation process. Close examination of these comments revealed issues that were not apparent from the quantitative data. Specifically, three themes emerged from the comments. One theme relates to alignment with the EALRs. Several experts commented on the lack of alignment in three specific areas related to the EALRs. Specifically, they pointed out the lack of alignment between the course outcomes and EALR 1.1.5 Benchmark 3 (Appendix A) and the course outcomes and EALR 1.2.2 (Appendix B). The EALRs in question refer to several aspects of students' learning surrounding evolution and

Four of the ten experts commented on the lack of alignment between EALR 1.2 .2 and EALR 1.1.5 Benchmark 3, and the course outcomes. Typical comments included statements such as the following, "EALR 1.2 is less explicitly reflected in outcomes," (Expert 2). Two experts commented on the lack of alignment regarding the concept of speciation. Experts felt that as currently developed, the course adequately explored the theory of evolution and the concepts of adaptation and biological diversity, but was not strong enough in the area of speciation. Likewise, experts felt the course currently explores classification by structural and cellular characteristics, but could do a better job

continued on page 578 


\section{Helping Hands}

continuation from page 576

exploring the classification by biochemical and genetic means. This finding troubled us.

Standards in education have several goals, such as making assessments more objective, enabling communication regarding student achievement, making goals clearer to students (and their parents), and clarifying what a teacher is supposed to teach. The concept of speciation is one core component of this unit. During the planning stages, the biology teachers gave equal weight to adaptation, speciation, and biological diversity. Although the lack of alignment is relatively easy to correct, it is troubling that complete alignment was not demonstrated. Realistically, until changes and modifications are made to the course outcomes, course activities, and assessments, student learning of classification and evolution is incomplete. Rather than wait for students to struggle with this part of the assessment (and receive lower scores), Ms. Ketover and her colleagues will make adjustments to this section of the curriculum.

\section{Parallel Student Achievement Benchmarks}

The second main theme of this study related to the construction of the student achievement benchmarks. Student achievement benchmarks identify what a student should be able to know, understand, and do at the basic, proficient, and mastery levels. Numerous comments focused on the parallels, or lack thereof, in the construction of the student achievement benchmarks and the implications for both content and cognitive process alignment. Typical comments included: “... some ... non-parallel constructions appear among ... the student achievement benchmarks," (Expert 2) and "Content of benchmarks is right on target ... [but] in moving through cognitive processes, two of the outcomes have minimal and/or overlapping transitions from basic to proficient, or proficient to mastery," (Expert 5).

Simply put, the experts expressed the need for benchmarks that addressed both the content and the process skills covered in the course outcomes. This finding of the study is significant because learning goals for students should be "specific and clear versus vague and general, hard and challenging versus simple and easy, goals that were set at the upper limit of the students' capacities versus their current performance levels" (Sadler, 1989, p. 129). The types of goals that Sadler is discussing are the goals that Mrs. Ketover and her colleagues are interested in setting for the students.

For example, the benchmarks could be redrafted to address progressive cognitive skill layering combined with content at each level. Perhaps the basic benchmark for classification would involve defining classification and stating why it is important. For the proficient benchmark, students would use an existing classification key to categorize focal organisms according to their structural, cellular, biochemical, and genetic characteristics. At the mastery level, they could construct and evaluate an original classification key. The cognitive processes progress from simple recall to more complex application and synthesis, using more content knowledge as one moves from basic to mastery benchmarks. Although several experts agreed on the need for clearer parallel construction, what the teachers changes, as well as how Kentridge's teachers made these changes, was open to various interpretations.

\section{Experts in Disagreement}

The third and final theme of the study involved some conflicting scoring and comments made by the experts. In two categories, namely the scoring of the alignment between the student achievement benchmarks and assessments and the outcomes and assessments, several experts disagreed completely. Four experts made comments relating to classification and six experts made comments relating to evolution in this regard. For example, Expert 9 stated that, "... the evolution assessments are aligned and thorough," while Expert 10 felt that the "Evolution match between student achievement and assessment doesn't work for me." For several reasons, this finding is problematic.

Students can be assessed to "identify improvements needed in science instruction and programs, to convey expectations to students, parents, teachers, and administrators, and to monitor the status of individuals, classes, districts, states, and the nation" (Doran et al., 1994). More importantly, "using assessment for informing and improving instruction is key to effective teaching and learning" (Stepanek, 1997, p. 2). Given the fact, however, that the experts split evenly regarding the adequacy of the alignment regarding the course assessments, it is difficult for us to identify the changes that need to be made. Unlike the other two themes, the evaluators gave no clear direction regarding this matter. Perhaps this is to be expected. Shepardson (1996) concluded that: 1) the science content we know influences the way we teach and assess, as well as what we teach and assess, 2) the pedagogy we know influences the science content we teach and assess and, 3 ) what we know about assessment influences how we teach and the science content we teach (Shepardson, 1996, p. 268). It appears that the findings of this study may concur with the Shepardson's conclusions.

Perhaps these experts are disagreeing due to their knowledge of science content, pedagogy, and 
assessment. They have vastly different educational backgrounds and experiences in the classroom. Also, each expert has varying degrees of assessment expertise. As one develops more knowledge of teaching and learning, and experiences more educational environments, one is able to observe and comment upon different things. Perhaps the perspectives of each expert were so unique that we were unable to determine the consensus of the experts based solely on their comments. In the future, we will consider recruiting a group with similar backgrounds and experiences, in the hopes that their feedback will converge on more specific issues and recommendations for alignment.

\section{Challenges of Alignment}

Webb (1997) defined alignment as the "degree to which expectations and assessments are in agreement and serve in conjunction with one another to guide the system toward students learning what they are expected to know and do" (p. 4). Alignment is challenging in practice for a number of reasons. First, expectations and assessments are typically located in different documents. Using multiple documents (e.g., course outcomes, student achievement benchmarks, and course assessments) poses a challenge for teachers when they try to interpret the overall picture of the expectations and assessments. Another challenge is the lack of a common language between the expectations and assessments. Finally, a third challenge is the fact that both expectations and assessments tend to change over time in response to new policies and political environments. Assessments must be fair and aligned with the curriculum.

As an initial venture into examining alignment using expert review, we experienced some challenges similar to those mentioned by Webb. However, the gains made by this new information allow us to make changes before students actually take high stakes tests. As we have seen in other states, test scores are the litmus test for curricular alignment and effective instruction. If scores reflect effective alignment, it behooves teachers at Kentridge to minimize the gaps before such scores are published. Using experts is one way to improve that alignment in a non-threatening, constructive way.

\section{Implications for Future Practice}

In 1999, Laguardia et al. published a case study of five Washington teachers. The researchers concluded, "... even those educators who are genuinely interested in reform have a feeling of overload, isolation, fragmentation, and increasing despair" (p. 4). We certainly relate these feelings. At times, it is a battle to take one day and one task at a time. Our study demonstrates that positive and constructive feedback can be generated through expert review. Without a doubt, more expert review is needed (and desired) in the area of standards and assessment at Kentridge High School.

In this study, experts were only asked to review the documents related to one unit of study in the biology course. There are several other units of study in the biology course, as well as the documents generated for other courses at the school. It would be intriguing to see if the experts' comments and scoring were similar for other units in biology and for other courses. Also, further discussion is needed when experts disagree about the adequacy of alignment between documents (i.e., the alignment between instructional documents and course assessments). Furthermore, the topic of this study was not the quality of the course outcomes, student achievement benchmarks, and assessments, but their alignment (or lack thereof). At some point in future, Kentridge High School teachers will examine these issues. In terms of our practice, this study reinforced the need to avoid creating and attempting to align course outcomes, benchmarks, and assessments in isolation.

\section{Conclusion}

In summary, the findings of this research study demonstrate that ten experts determined Ms. Ketover and her colleagues to be at least competent in their attempts to align several documents. Furthermore, the experts found that there were several areas of weakness related to alignment between standards and course outcomes. Interestingly, experts' opinions of the alignment between documents were in direct conflict with one another making correction of any underlying issues problematic. This study points to the potential need for future research regarding the types of assessments and alignment issues. Accountability in education is not a passing trend. We, as teachers, need to reach out to others as we strive to improve our efforts relating accountability in our individual classrooms.

\section{References}

Academic Achievement and Accountability Commission. About the Commission. Retrieved August 31, 2003 from the Academic Achievement and Accountability Commission web site: http://www.k12.wa.us./ accountability/.

Beasley, W. (1992). Toward student autonomy. The Science Teacher, 59(6), 46-49.

Biddle, B. J. \& Sheldon, K. M. (1998). Standards, accountability, and school reform: perils and pitfalls. Teachers College Record, 100(1), 164-180.

Blank, R. K. \& Dalkilic, M. (1990). State Indicators of Science 
and Mathematics Education. Washington, DC: Council of Chief State School Officers, State Educational Assessment Center.

Conly, D. T. \& Goldman, P. (1998). How Educators Process and Respond to State-Level Education Reform Policies: the Case of Oregon. Annual Meeting of the American Educational Research Association. (ERIC Document Reproduction Service No. ED 421 773)

Corbett, H.D. \& Wilson, B. L. (1995). Statewide Testing and Local Improvement: An Oxymoron. (ERIC Document Reproduction Service No. ED 374 551).

Din, F. S. (1996). The Impact of Kentucky State Testing on Educational Practices in Kentucky Public Schools. Kentucky: ERIC Clearinghouse on Educational Management. (ERIC Document Reproduction Service No. ED 405352).

Doran, R.L., Lawrenz, F. \& Helgeson, S. (1994). Research on assessment in science. In D. Gabel (Ed.), Handbook of Research on Science Teaching and Learning, 388-442. New York: Macmillan Publishing Company.

Laguardia, A., Grisham, D., Gallucci, C., Jamison, S., Brink, B. \& Peck, C. (April 19-23, 1999). A School-University Partnership's Involvement in State Mandated Reform: The Impact of a Teacher-Based Professional Development Model on Teachers. Annual Meeting of the American Educational Research Association. (ERIC Document Reproduction Service No. ED 430 935).

Lane, S., Parke, C.S., Stone, C.A. (1998). Consequences of the Maryland School Performance Assessment Program. (ERIC Document Reproduction Service No. 434927 ED).

Lutz, F. \& Maddirala, J. (1990). Stress, burnout in Texas teachers and reform mandated accountability. Educational Research Quarterly, 14 (2), 10-21.

Manzo-Kennedy, K. (1998). Many States' Standards Add Up to " $D$ " in Review. http://www.edweek.org/ew/vol-17/ 42 ford.h17.

McCloskey, W. (1993). Matching Assessment to the Curriculum in a Systematic Science Reform Project. North Carolina: ERIC Clearinghouse on Educational Management. (ERIC Document Reproduction Service No. ED 358146).

McMahon, T. (1996). Collaborative Challenge Grant Evaluation Plan for Waukegan, Illinois. http:// www.ncrel.org/tandl/eval3.html.

McMillan, J., Myran, S. \& Workman, D. (1999). The Impact of Mandated Statewide Testing on Teacher's Classroom Assessment and Instructional Practices. (ERIC Document Reproduction Service No. ED 431 041).

NRC (National Research Council). (1996). National Science Education Standards. Washington, DC: National Academy Press.
Office of the Superintendent of Public Instruction. Washington Assessment of Student Learning. Retrieved August 31, 2003 from the Office of the Superintendent of Public Instruction web site: http://www.k12.wa.us/ curriculuminstruct/background/default.asp

Ohanian, S. (2001). News from the Test Resistance Trail. http://www.pdkintl.org/kappan/koha0101.htm.

Olson, L. (1999). Rating the standards. Education Week, 18 (17), 107-109.

Olson, L. (1999). Shining a spotlight on results. Education Week, 18(17), 8-10.

O'Sullivan, C.Y. (1997). NAEP 1996 Science Report Card for the Nation and States. Findings from the National Assessment of Educational Progress. (ERIC Document Reproduction Service No. ED405221).

Quilter, S. \& Chester, C. (1998). Inservice Teachers' Perception of Educational Assessment. (ERIC Document Reproduction Service No. ED 425152).

Rios, J. (2002). Examining Relationships Between Science Standards and Science Teaching. Manuscript in preparation.

$\rightarrow$ Sadler, D. R. (1989). Formative Assessment and the Design of Instructional Systems. Instructional Science, 18(2), 119144.

Shannon, S. (2000). WEA Board Confirms Commitment to Ed Reform; Says No to WASL as Sole Measurement. http://wa.nea.org/Jumps/2000_2/WASL6-19.htm.

Shepardson, D. (1997). Developing alternative assessment using the benchmarks. Science \& Children, 35(2), 34-40.

$\rightarrow$ Shepardson, D. \& Adams, P. E. (1996). Coming to know and understand alternative assessment in science. Journal of Science Teacher Education, 7(4), 267-282.

Stager, S.F. \& Green, K.E. (1984). Teachers' Use of Tests and Attitudes Towards Classroom and Standardized Tests. (ERIC Document Reproduction Service No. ED 252 575).

Stepanek, S. (1997). Assessment Strategies To Inform Science and Mathematics Instruction. (ERIC Document Reproduction Service No. ED415114).

Ward, J.G. (1980). Teachers and Testing: A Survey of Knowledge and Attitudes. (ERIC Document Reproduction Service No. ED 193 258).

Washington Commission on Student Learning. (1998). Essential Academic Learning Requirements Technical Manual. Olympia, WA: Office of the Superintendent of Public Instruction.

Webb, N. L. (1997). Criteria for Alignment of Expectations and Assessments in Mathematics and Science Education (ERIC Document Reproduction Service No. ED414305).

$\rightarrow$ Wood, T. (1988). State-mandated accountability as a constraint on teaching and learning science. Journal of Research in Science Teaching, 25(8), 631-641.

continued on page 582 
Helping Hands

continuation from page 580

\section{Appendix A}

\section{Outcome, Benchmark $\&$ Assessment Overview for Classification}

EALRs Addressed

EALR 1.1: Use properties to identify, describe, and categorize substances, materials, and objects, and use characteristics to categorize living things.

EALR 1.1.5, Benchmark 2. Categorize plants and animals into groups according to how they accomplish life processes and by similarities and differences in external and internal structures.

EALR 1.1.5, Benchmark 3. Classify organisms into distinct groups according to structural, cellular, biochemical, and genetic characteristics.

\section{Classification Course Outcome}

Describe the purpose and apply the method for classifying organisms.

Basic Benchmark: Define classification and state why it is important.

Proficient Benchmark: Using an existing classification key, classify targets.

Mastery Benchmark: Construct and original classification key to enable classification of targets.

\section{Assessments}

1. Classification Introduction Activity

2. Classification Group Work

3. Salamander Classification (existing key)

4. Tree Identification (existing key)

5. Wildflower Classification (original key)

6. Primate Classification (original key)

7. Classification Quiz

8. Culminating Activity

9. Biology Pre/Post Test Questions

\section{Appendix B}

\section{Outcome, Benchmark \& Assessment Overview for Evolution}

EALRs Addressed

EALR 1.2: Understand how interactions within and among systems cause changes in matter and energy.

EALR 1.2.2: Investigate and examine the scientific evidence used to develop theories for evolution, speciation, adaptation, and biological diversity.

\section{Evolution Course Outcome \#1}

Define evolution and provide possible supporting evidence for the argument of a common ancestor for all life forms on Earth.

Basic Benchmark: Define evolution and identify the lines of evidence.

Proficient Benchmark: Define evolution and identify lines of evidence using specific examples to explain.

Mastery Benchmark: Identify the points of evidence using specific examples. Critically evaluate the strengths and weaknesses of each line of evidence.

\section{Evolution Course Outcome \#2}

Identify and describe the alternative mechanisms (spontaneous generation, inheritance of acquired characteristics, and natural selection) for evolution.

Basic Benchmark: Identify and describe the alternative mechanisms for evolution.

Proficient Benchmark: Compare and contrast the alternative mechanisms for evolution.

Mastery Benchmark: Critically evaluates the strengths and weaknesses of each mechanism through application to a scenario.

\section{Assessments}

1. Variation Lab

2. Adaptation Identification Activity

3. Scenario Activity

4. Natural Selection Lab

5. Organism/Environment Prediction Activity

6. Biology Pre/Post Test Questions 